\title{
Dural Arteriovenous Fistulas of the Foramen Magnum Region: Clinical Features and Angioarchitectural Phenotypes
}

\author{
(D) M.T. Caton, (D).H. Narsinh, (D) A. Baker, (D).F. Dowd, (DR.T. Higashida, (DD.L. Cooke, (DS.W. Hetts, (D) V.V. Halbach, and
} (D) M.R. Amans

\section{ABSTRACT}

BACKGROUND AND PURPOSE: AVFs of the foramen magnum region, including fistulas of the marginal sinus and condylar veins, have complex arterial supply, venous drainage, symptoms, and risk features that are not well-defined. The purpose of this study was to present the angioarchitectural and clinical phenotypes of a foramen magnum region AVF from a large, single-center experience.

MATERIALS AND METHODS: We retrospectively reviewed cases from a 10-year neurointerventional data base. Arterial and venous angioarchitectural features and clinical presentation were extracted from the medical record. Venous drainage patterns were stratified into 4 groups as follows: type $1=$ unrestricted sinus drainage, type $2=$ sinus reflux (including the inferior petrosal sinus), type $3=$ reflux involving sinuses and cortical veins, and type $4=$ restricted cortical vein outflow or perimedullary congestion.

RESULTS: Twenty-eight patients (mean age, 57.9 years; $57.1 \%$ men) had 29 foramen magnum region AVFs. There were 11 (37.9\%) type 1, nine (31.0\%) type 2, six (20.7\%) type 3, and 3 (10.3\%) type 4 fistulas. Pulsatile tinnitus was the most frequent symptom (82.1\%), followed by orbital symptoms (31.0\%), subarachnoid hemorrhage (13.8\%), cranial nerve XII palsy (10.3\%), and other cranial nerve palsy (6.9\%). The most frequent arterial supply was the ipsilateral ascending pharyngeal artery $(93.1 \%$ ipsilateral, $55.5 \%$ contralateral), vertebral artery (89.7\%), occipital artery (65.5\%), and internal carotid artery branches (48.3\%).

CONCLUSIONS: We present the largest case series of foramen magnum region AVFs to date and show that clinical features relate to angioarchitecture. Orbital symptoms are frequent when sinus reflux is present. Hemorrhage was only observed in type 3 and 4 fistulas.

ABBREVIATIONS: $\mathrm{FMR}=$ foramen magnum region; IJV $=$ internal jugular vein

D ural AVFs of the foramen magnum region (FMR) comprise a rare subgroup of intracranial arteriovenous shunts occurring at the marginal sinus and condylar veins. ${ }^{1}$ These FMR AVFs are thought to represent between $1.5 \%$ and $4.2 \%$ of cranial shunting lesions. ${ }^{2,3}$ These lesions are anatomically complex, owing to the functional and anatomic variability of venous drainage at the craniocervical junction. ${ }^{4-6}$ The marginal sinus is an inconstant

Received January 10, 2021; accepted after revision February 26.

From the Department of Radiology and Biomedical Imaging, Interventional Neuroradiology Section, University of California, San Francisco, San Francisco, California.

This work was supported by National Heart Lung-Blood Institute of the National Institutes of Health under award No. R56 HL149124-01.

Paper previously presented, in part, at: Annual Meeting of the American Society of Neuroradiology, May 22-26, 2021; virtual.

Please address correspondence to M. Travis Caton Jr, MD, University of California, San Francisco, 505 Parnassus Ave, Room L349, San Francisco, CA 94143; e-mail: michael.caton2@ucsf.edu; @traviscaton

- Indicates open access to non-subscribers at www.ajnr.org

Indicates article with online supplemental data.

http://dx.doi.org/10.3174/ajnr.A7152 ringlike intradural sinus along the rim of the foramen magnum and is frequently undetectable on noninvasive imaging in normal physiologic states. ${ }^{7}$ The marginal sinus communicates with a network of venous channels, including the condylar veins (anterior, posterior, and lateral), the condylar confluence, and the inferior petrosal sinus, serving to redirect blood flow between the parallel venous egress pathways of the jugular vein and vertebral venous plexus (Fig 1). As a consequence, pressurization of this FMR venous network can manifest with a spectrum of symptoms ranging from pulsatile tinnitus to myelopathy. Retrograde pressurization of the cavernous sinus via the inferior petrosal sinus may also generate orbital chemosis and extraorbital muscle palsies that may masquerade as carotid cavernous fistulas. ${ }^{8}$

An FMR AVF at high risk of hemorrhage or causing debilitating symptoms can be treated endovascularly with low morbidity. ${ }^{1}$ Both transvenous and transarterial approaches have been described. ${ }^{9-12}$ Successful treatment of FMR AVFs demands rigorous preparation and knowledge of both the arterial supply and venous drainage patterns to achieve a durable cure and avoid nontarget embolization. 
However, as with other classes of AVF, observation is appropriate for low-risk lesions. ${ }^{13}$ Therefore, knowledge of the holistic structure and behavior of the shunt, including comprehensive evaluation of the arterial and venous anatomy of the fistula, is essential for treatment planning and complication avoidance.

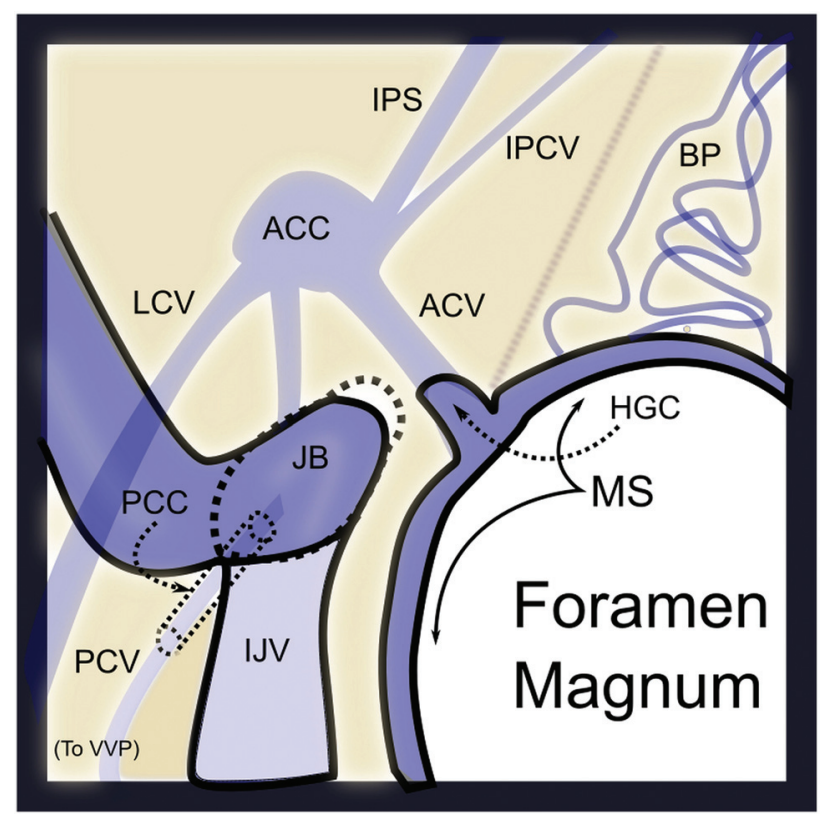

FIG 1. Venous anatomy of the FMR from above. The marginal sinus (MS) lines the margin the foramen magnum and connects to the basilar plexus (BP) anteriorly, the anterior condylar vein (ACV) laterally via the hypoglossal canal (HGC), and the suboccipital cavernous sinus inferiorly (not shown). The anterior condylar vein (AVC) connects with the anterior condylar confluence (ACC), which, in turn, communicates with the inferior petrosal sinus (IPS) and inferior petroclival vein (IPCV) and posteriorly with the lateral condylar vein (LCV), and the jugular bulb and internal jugular vein (JB/IJV). The posterior condylar (emissary) vein (PCV) exits via the posterior condylar canal (PCC).
McDougall et $\mathrm{al}^{1}$ at the University of California, San Francisco proposed a grading system for FMR AVF, classifying shunts by their pattern of venous drainage. In this model, low-risk shunts (grade I) have unrestricted antegrade drainage via the internal jugular vein (IJV) system, whereas intermediate (grade II) lesions show partial or restricted IJV outflow. High-risk shunts (grade III) drain exclusively via superficial venous channels. Spittau et $\mathrm{al}^{14}$ proposed a modification to this taxonomy based on the dominant pattern of drainage, type 1: dominant antegrade flow (jugular or vertebral venous plexus), type 2: dominant retrograde flow (petro$\mathrm{sal} \rightarrow$ cavernous), and type 3 : dominant pial/perimedullary reflux. Because the current neuroendovascular literature is confined to small case reports and series, the validity of these proposed angiographic-clinical relationships is uncertain.

The purpose of this study was to elucidate the relationship between vascular angioarchitecture and clinical presentation by retrospectively evaluating a large single-institution case series.

\section{MATERIALS AND METHODS Data Acquisition}

The neurointerventional data base of a single, large, tertiary hospital (University of California, San Francisco) was retrospectively reviewed between January 2010 and November 2020 under an institutional review board-approved protocol in which informed consent was waived. Search inclusion criteria were confined to patients who underwent conventional angiography at our hospital and who were diagnosed with fistulas of the marginal sinus, condylar veins (anterior, lateral, posterior, and condylar confluence), or foramen magnum during the prespecified time interval. Inclusion mandated complete angiography including selective DSA of the bilateral internal and external carotid arteries and bilateral subclavian arteries including the deep and ascending cervical branches, and dedicated angiography of the posterior fossa (vertebral artery injection). Cases in which the original angiographic diagnosis was equivocal or discordant with intraoperative

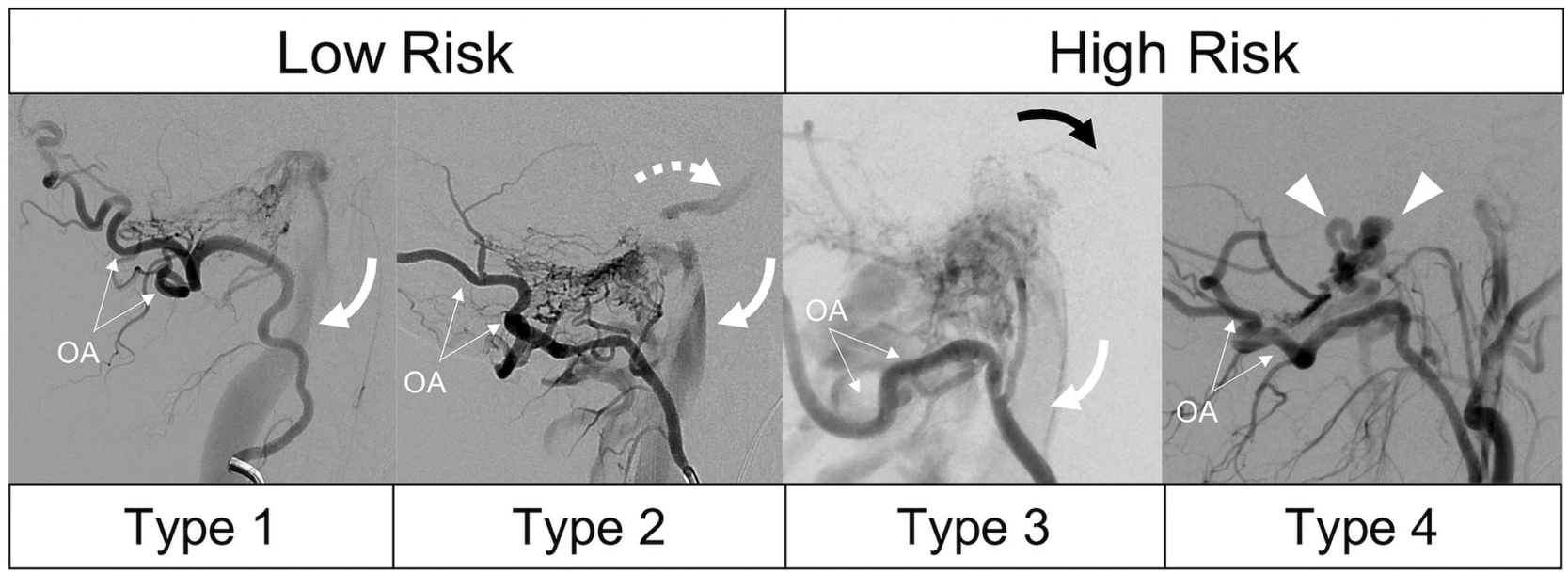

FIG 2. Modified grading system for FMR-AVFs shown in 4 patients having undergone lateral occipital artery (OA) injection DSA. Type 1 shows unrestricted drainage via the IJV (curved arrow) without reflux. Type 2 shows both antegrade drainage (curved arrow) and sinus reflux (dashed arrow, inferior petrosal sinus). Type 3 lesions are differentiated by the presence of cortical venous reflux, in this case, pontine perforating veins (black arrow) in addition to sinus drainage (white arrow). Type 4 lesions have restricted, exclusive drainage via cortical veins (arrowheads) without a coexisting sinus drainage pathway. 


\begin{tabular}{|c|c|c|c|c|c|c|}
\hline \multirow[b]{2}{*}{$\begin{array}{c}\text { Venous Angioarchitectural } \\
\text { Type }\end{array}$} & \multicolumn{6}{|c|}{ Clinical Presentation (\% of Cases) } \\
\hline & $\begin{array}{c}\text { Pulsatile Tinnitus and/or } \\
\text { Bruit }\end{array}$ & $\begin{array}{c}\text { Orbital } \\
\text { Symptoms }\end{array}$ & $\begin{array}{l}\text { CN XII } \\
\text { Palsy }\end{array}$ & Myelopathy & Hemorrhage & Headache \\
\hline Type 1 ( $n=11)$ & $90.9 \%$ & $9.1 \%$ & $0.0 \%$ & $0.0 \%$ & $0.0 \%$ & $27.3 \%$ \\
\hline Type $2(n=9)$ & $100.0 \%$ & $44.4 \%$ & $22.2 \%$ & $0.0 \%$ & $0.0 \%$ & $44.4 \%$ \\
\hline Type $3(n=6)$ & $66.7 \%$ & $33.3 \%$ & $0.0 \%$ & $0.0 \%$ & $16.7 \%$ & $50.0 \%$ \\
\hline Type $4(n=3)$ & $33.3 \%$ & $33.3 \%$ & $0.0 \%$ & $33.3 \%$ & $66.7 \%$ & $66.7 \%$ \\
\hline
\end{tabular}

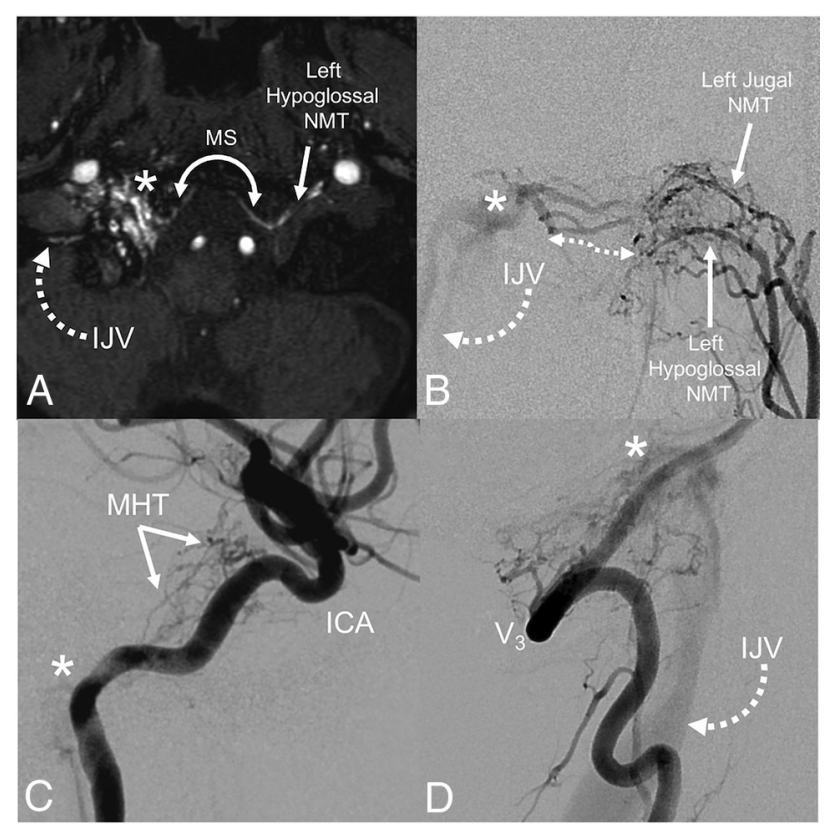

FIG 3. Arterial anatomy of a typical type 1 FMR AVF. TOF-MRA $(A)$ of the skull base shows abnormal flow-related enhancement in the right hypoglossal canal, corresponding to a fistula (asterisk). Arterial supply from the contralateral ascending pharyngeal artery (hypoglossal branch) crosses the foramen magnum and drains via the IJV. Relative anatomy: an anterior-posterior DSA with injection of the left ascending pharyngeal artery $(B)$ shows hypertrophied arterial channels (double-sided arrow). Lateral DSA of the right ICA (C) shows supply to the fistula (asterisk) from the meningohyposphyseal trunk (MHT). D, Lateral DSA of the right vertebral artery $\left(V_{3}\right)$ shows direct contribution to fistula (asterisk) and drainage via the IJV. NMT indicates neuromeningeal trunk; MS, marginal sinus.

findings were reviewed by an experienced neurointerventionalist (M.R.A.) and were excluded if a shunt of the FMR was not definitely identified. Patients with angiographic work-up at other hospitals were excluded.

Demographic characteristics including clinical presentation were extracted from the clinical and procedural notes. For this purpose, we defined "orbital symptoms" as including exophthalmos, chemosis, episcleral venous engorgement, or extraorbital muscle palsy. Each cerebral angiogram was reviewed to gather arterial feeder vessels and venous drainage patterns. Fistulas were subclassified as marginal sinus, anterior condylar vein, posterior condylar vein, or lateral condylar vein on the basis of the venous location of the shunt. Venous drainage was classified according to a modified version of the McDougall grading system: type $1=$ unrestricted sinus drainage, type $2=$ sinus reflux (including inferior petrosal sinus), type $3=$ reflux involving sinuses and cortical veins, and type $4=$ restricted cortical vein outflow or perimedullary congestion (Fig 2). All values are reported as mean (SD).

Statistical comparison of symptom prevalence between groups was performed using a 2-tailed Fisher exact test, and comparison of mean arterial feeder numbers across groups was performed using the Kruskal-Wallis test, with $P$ values $<.05$ considered significant.

\section{RESULTS}

Retrospective review of neuroangiographic reports obtained between January 2010 and November 2020 initially identified 36 patients with a possible FMR AVF. We excluded 8 patients: Of these, 2 were patients initially treated outside the prespecified time interval, 1 patient's final diagnosis was a small medullary arteriovenous malformation confirmed on resection, and 5 patients with possible FMR AVF were excluded after review by the senior author (M.R.A.) due to the uncertainty of the fistulous site or incomplete angiographic characterization after review of DSA images. We, therefore, included 28 patients with 29 FMR AVFs in the final analysis ( 1 patient had 2 discrete fistulas involving the marginal sinus and lateral condylar vein). The mean patient age was 57.9 (SD, 15.2) years, and $57.1 \%$ of patients were men.

\section{Venous Drainage Patterns, Risk Stratification, and Clinical Presentation}

The most common fistulous sites were the marginal sinus $(21 / 29$, $72.4 \%)$, anterior condylar vein, $(4 / 29,13.8 \%)$, posterior condylar vein $(2 / 29,6.9 \%)$, and lateral condylar vein $(2 / 29,6.9 \%)$. Using the modified University of California, San Francisco criteria (Fig 2), we classified 11/29 (37.9\%) FMR AVFs as type one, 9/29 (31.0\%) as type two, $6 / 29(20.7 \%)$ as type 3 , and $3 / 29(10.3 \%)$ as type 4 . The most frequent clinical symptoms among all patients included pulsatile tinnitus (82.8\%) and orbital symptoms (27.6\%). Less frequent clinical presentations included subarachnoid hemorrhage (10.3\%), hypoglossal nerve palsy (6.9\%), trigeminal nerve palsy (6.9\%), and myelopathy (3.4\%). One patient in this series $(1 / 29,3.4 \%)$ was asymptomatically diagnosed during routine angiographic followup of a resected AVM. Headache was common in all groups, with an overall prevalence of $48.3 \%$, increasing in frequency at higher venous angioarchitectural types, ranging from $27.3 \%$ of patients (type 1) to $66.7 \%$ (type 4 ).

The relationship of clinical presentation to venous angioarchitectural risk type is summarized in the Table. Orbital symptoms were present in $40 \%$ of cases associated with some degree of venous sinus reflux (type 2 or 3 ) compared with $9.1 \%$ of patients with intact antegrade sinus drainage, though this difference was not significant $(P=.13)$. Hypoglossal palsy was seen in $2 / 9$ $(22.2 \%)$ cases of type 2 FMR AVF as was trigeminal nerve palsy 


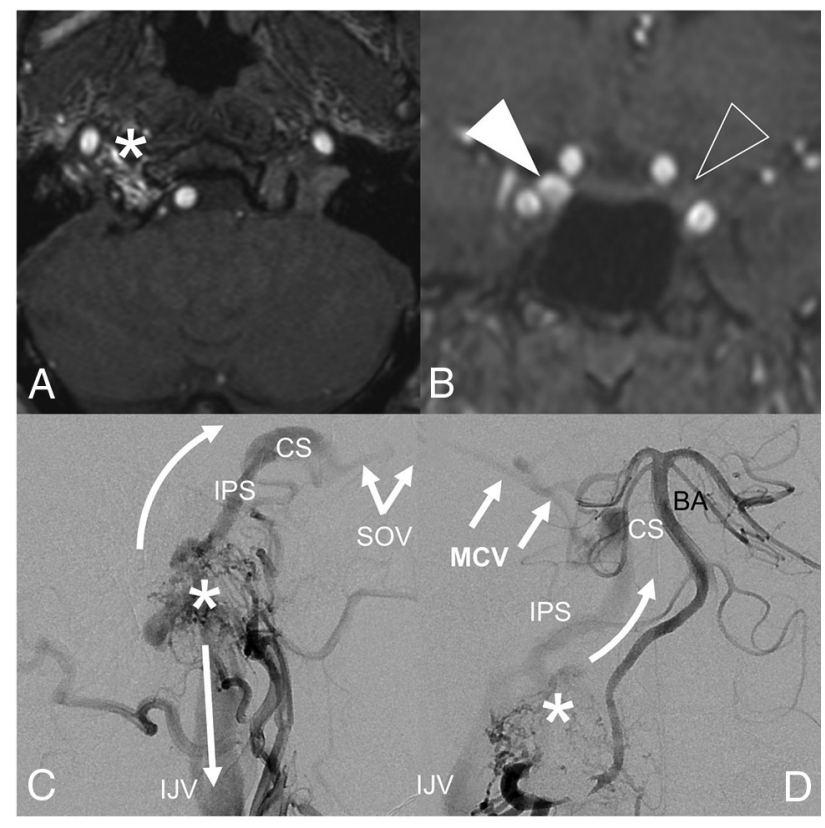

FIG 4. A type 3 FMR-AVF with clinical features mimicking a carotid cavernous fistula. MRA of the FMR $(A)$ shows flow-related enhancement in the right hypoglossal canal, corresponding to an anterior condylar vein fistula site. Coronal MRA (B) shows asymmetric flowrelated enhancement of the right (white arrowhead) relative to left (clear arrowhead) cavernous sinuses. Lateral-projection DSA of the right ascending pharyngeal artery $(C)$ shows the fistula (asterisk) with antegrade drainage via the IJV (straight arrow) and reflux via the inferior petrosal sinus (IPS, curved arrow) extending to the cavernous sinus (CS) and superior ophthalmic vein (SOV), resulting in proptosis and chemosis. Anterior-posterior DSA of the right vertebral artery (D) shows reflux via the IPS and CS, which continues to the middle cerebral vein (MCV), making this a high-risk type 3 fistula. The asterisk represents the fistulous shunt site. BA indicates the basilar artery.

$(2 / 9,22.2 \%)$. Hemorrhage was seen exclusively in FMR AVFs with cortical vein reflux (type 3 or 4 ). One patient with a type 4 FMR AVF presented with cervical myelopathy.

\section{Arterial Supply}

The overall mean number of arterial feeders per fistula was 5.7 (SD, 3.00). The frequency of each arterial feeder is summarized in the Online Supplemental Data, and an illustrative example of a type 1 lesion is shown in Fig 3. Eighteen of 29 (62.1\%) FMR AVFs derived supply from at least 1 contralateral artery. Arterial feeders present in $>50 \%$ of all patients with FMR AVF included the ipsilateral ascending pharyngeal artery (93.1\%), ipsilateral vertebral artery (89.7\%), ipsilateral occipital artery $65.5 \%$, and contralateral ascending pharyngeal artery (55.2\%). Other frequent arterial feeders included the meningohypophyseal and inferolateral trunks of the internal carotid artery $(48.3 \%$ ipsilateral and $31.0 \%$ contralateral), ipsilateral middle meningeal artery (31.0\%), posterior auricular artery $(31.0 \%)$, and contralateral vertebral artery (28.6\%). There was no significant difference in the number of arterial feeders by venous risk group $(P=.18)$ : The mean number of feeders for type 1 was 5.6 (SD, 3.4), type two, $6.8(\mathrm{SD}, 2.1$ ), type three, $6.2(\mathrm{SD}, 3.1)$, and type four, 2.3 (SD, 1.5). The fraction of cases with at least 1 contralateral arterial feeder was $63.6 \%$ for type one, $77.8 \%$ for type two, $50.0 \%$ for type 3 , and $33.0 \%$ for type 4 .

\section{DISCUSSION}

This study represents the largest series of FMR AVFs to date and clarifies the behavior of this uncommon form of intracranial shunt, revealing 4 distinct clinical-angiographic phenotypes. FMR AVFs were under-represented in previous studies, for example, comprising only $1.5 \%$ of cases in the cohort from which the Cognard classification was derived. ${ }^{2}$ This study, therefore, builds on prior work $^{1,3,14}$ by establishing a classification system specific to FMR AVF, incorporating both risk and symptoms toward appropriate therapy selection.

McDougall et $\mathrm{al}^{1}$ were the first to systematically describe fistulas of the marginal sinus in a series of 14 patients. They defined 3 clinical phenotypes based on the restriction of jugular outflow and the presence of cortical venous reflux. More recently, Choi et $\mathrm{al}^{3}$ described 10 fistulas of the hypoglossal canal (anterior condylar vein), noting that orbital symptoms and myelopathy were present only in cases with restriction of antegrade sinus outflow, extending the notion that clinical presentation is a manifestation of venous drainage and therefore an overall risk. In a case series and in a systematic review of 120 cases of FMR AVF (115/120, 95.8\% from the literature), Spittau et $\mathrm{al}^{14}$ modified the McDougall taxonomy on the basis of clinical phenotypes, emphasizing the dominant pattern of venous drainage: $1=$ antegrade sinus, $2=$ retrograde sinus with or without antegrade drainage/cortical venous reflux, and $3=$ dominant cortical venous or perimedullary reflux. They showed that this angiographic classification schema corresponds well with clinical manifestations. However, due to inclusion of a subjective element (dominance) and lack of primary angiographic data in $>90 \%$ of included cases, the reproducibility and generalizability of this scale are uncertain. In addition, the Spittau criteria do not differentiate the binary presence or absence of cortical venous reflux, a feature that has important implications for hemorrhagic risk and mortality. ${ }^{15,16} \mathrm{We}$, therefore, differentiated type $2(60 \%)$ and 3 lesions (40\%) on the basis of the presence of cortical venous reflux despite a similar prevalence of orbital symptoms $(44.3 \%$ versus $33.3 \%, P=1.0$, Fisher exact test) among patients with sinus reflux (Fig 4).

The principal finding of this study is that nearly all FMR AVFs present symptomatically (96.5\%), most with pulsatile tinnitus (82.3\%). While AVFs of the sigmoid and transverse sinuses are known causes of pulsatile tinnitus, the correlation of FMR AVF and pulsatile tinnitus is less established. Turbulence in the pressurized condylar veins and petrosal sinuses could plausibly result in conduction across the petrous bone, accounting for a high-pitched, pulse-synchronous tinnitus. In our experience, direct auscultation of the mastoid bone often reveals audible bruit in patients with FMR AVF. Given the observed association of pulsatile tinnitus and FMR AVF, vigilance of the posterior skull base is warranted on noninvasive imaging studies performed to evaluate pulsatile tinnitus. Advanced MR imaging techniques including contrast MR angiography, susceptibility mapping of deoxygenated hemoglobin, and arterial spin-labeling may aid in the diagnosis but care should be taken to avoid misinterpretation of artifactual signal in this 
region. ${ }^{17}$ Our findings also support results of previous work showing that the orbital symptoms are frequent in an FMR AVF with sinus reflux ( $40 \%$ of patients with type 2 or 3 ), a finding that may clinically mimic carotid cavernous fistula (Fig 4). ${ }^{8}$

In this series, high-risk presenting symptoms (myelopathy, hemorrhage) were seen exclusively in type 3 and 4 lesions. Type 1 and 2 FMR AVFs may, therefore, be considered low-risk when evaluating patients for treatment. This finding corroborates previously well-established risk features from the Borden and Cognard classification systems, in which cortical venous reflux is the key mediator of risk. ${ }^{2,18}$ Although the overall incidence of hemorrhage and myelopathy was low (13.7\%) relative to other cranial AVFs, the presence of orbital symptoms in $>25 \%$ of cases has important therapeutic implications. Left untreated, pressurization of the cavernous sinus can result in permanent vision loss and represents an urgent indication for therapy for the FMR AVF. ${ }^{19}$ We find that the presence (or absence) of orbital symptoms is a useful heuristic for stratifying patients. Although we did not find statistical difference, orbital symptoms were seen in $40 \%$ of patients with angiographic evidence of venous reflux (type 2/3) compared with $14.3 \%$ with none (type $1 / 4$ ). Still, the considerable overlap in orbital symptoms between ostensibly low-risk (type 2) and high-risk (type 3 ) lesions stresses the importance of angiography in the initial diagnostic work-up.

Djindjian and Merland ${ }^{20}$ first recognized the disproportionate impact of venous drainage over arterial supply in their taxonomy of cranial AVFs. Subsequent work has confirmed this as a tenet of risk stratification. ${ }^{15,21,22}$ Despite the emphasis on venous angioarchitecture, knowledge of the arterial supply is critical to inform treatment strategies. Curative endovascular treatment requires total obliteration of the network of arterial feeders; failure to recognize the contribution of a contralateral feeding artery could result in treatment failure and preclude repeat treatment. Our findings show that a contralateral arterial supply is present in $62.5 \%$ of cases. We found that dural supply from the internal carotid artery (48.3\% ipsilateral, $31.0 \%$ contralateral) and direct vertebral artery supply ( $89.7 \%$ ipsilateral, $27.6 \%$ contralateral) were common. Recognition of these and other potential hazardous collaterals is critical to prevent inadvertent reflux if transarterial liquid embolics are used. While this study is insufficiently powered to detect statistical differences in arterial supply across venous angioarchitectural types, we noted a general increase in the number of arterial feeders from type 1 through type 3, with the notable exception of type 4 FMR AVFs, which typically have fewer arterial feeders at presentation. These findings again emphasize the importance of meticulous pretreatment control angiograms to delineate the full extent of the arterial supply in FMR AVFs.

There are several important limitations of the current study. First, although this is the largest comprehensive angiographic review of FMR AVFs, our analysis is underpowered to detect robust differences among angioarchitectural groups. Moreover, we cannot define the natural history of FMR AVFs or the propensity for lesions to attain higher risk features across time, a phenomenon that was reported in $2 \%$ of patients in 1 study. ${ }^{13}$ We elected to aggregate fistulas of the FMR, including the condylar veins and marginal sinus, because these share many interconnections and common final drainage pathways. ${ }^{45,7,23}$ However, it is plausible that subgroups of FMR AVFs (eg, lateral-versus-posterior condylar veins) behave differently.

\section{CONCLUSIONS}

We report the clinical characteristics and detailed arteriovenous angioarchitecture of 29 FMR AVFs, defining 4 clinical-angiographic phenotypes. These fistulas have a wide range of clinical presentations that correlate to, but may not reliably predict, angiographic risk. The arterial supply and venous drainage patterns of FMR AVFs are equally variable; we, therefore, recommend thorough diagnostic angiography before treatment.

Disclosures: Christopher F. Dowd—UNRELATED: Other: Stryker, Comments: Chief Adjudicator for the EVOLVE Flow Diverter Clinical Trial.* Steven W. HettsUNRELATED: Consultancy: Stryker Neuorovascular, Route 92, Johnson \& Johnson, Siemens, Comments: Core Lab or Clinical Endpoints Committee for clinical trials, contract for angiography suite evaluation*; Stock/Stock Options: ThrombX Medical, Comments: equity in stroke device startup company. Matthew R. Amans-RELATED: Grant: National Institutes of Health; UNRELATED: Board Membership: MindRhythm Inc; Consultancy: Covidien, Stryker, MicroVention, Comments: Pipeline proctor, consultant, Precipitating Hydrophobic Injectable Liquid (PHIL), Data and Safety Monitoring Board. *Money paid to the institution.

\section{REFERENCES}

1. McDougall CG, Halbach VV, Dowd CF, et al. Dural arteriovenous fistulas of the marginal sinus. AJNR Am J Neuroradiol 1997;18:1565-72 Medline

2. Cognard C, Gobin YP, Pierot L, et al. Cerebral dural arteriovenous fistulas: clinical and angiographic correlation with a revised classification of venous drainage. Radiology 1995;194:671-80 CrossRef Medline

3. Choi JW, Kim BM, Kim DJ, et al. Hypoglossal canal dural arteriovenous fistula: incidence and the relationship between symptoms and drainage pattern: clinical article. J Neurosurg 2013;119:955-60 CrossRef Medline

4. San Millán Ruíz D, Gailloud P, Rüfenacht DA, et al. The craniocervical venous system in relation to cerebral venous drainage. AJNR Am J Neuroradiol 2002;23:1500-08 Medline

5. de Oliveira E, Rhoton AL, Peace D. Microsurgical anatomy of the region of the foramen magnum. Surg Neurol 1985;24:293-352 CrossRef Medline

6. Takahashi S, Sakuma I, Omachi K, et al. Craniocervical junction venous anatomy around the suboccipital cavernous sinus: evaluation by MR imaging. Eur Radiol 2005;15:1694-700 CrossRef Medline

7. Tubbs RS, Ammar K, Liechty $\mathrm{P}$, et al. The marginal sinus. $J$ Neurosurg 2006;104:429-31 CrossRef Medline

8. Turner RD, Gonugunta V, Kelly ME, et al. Marginal sinus arteriovenous fistulas mimicking carotid cavernous fistulas: diagnostic and therapeutic considerations. AJNR Am J Neuroradiol 2007;28:191518 CrossRef Medline

9. Tanoue S, Goto K, Ota S. Endovascular treatment for dural arteriovenous fistula of the anterior condylar vein with unusual venous drainage: report of two cases. AJNR Am J Neuroradiol 2005;26:195559 Medline

10. Takemoto K, Tateshima S, Rastogi S, et al. Onyx embolization of anterior condylar confluence dural arteriovenous fistula. J Neurointerv Surg 2014;6:e13 CrossRef Medline

11. Choi HS, Kim DI, Kim BM, et al. Endovascular treatment of dural arteriovenous fistula involving marginal sinus with emphasis on the routes of transvenous embolization. Neuroradiology 2011;54:163-69 CrossRef Medline

12. Cyril C, Ofélia M, Hervé D. Dural arteriovenous fistula involving the anterior condylar canal. J Neuroimaging 2013;23:425-28 CrossRef Medline

13. Satomi J, van Dijk JM, Terbrugge KG, et al. Benign cranial dural arteriovenous fistulas: outcome of conservative management based 
on the natural history of the lesion. J Neurosurg 2002;97:767-70 CrossRef Medline

14. Spittau B, Millán DS, El-Sherifi S, et al. Dural arteriovenous fistulas of the hypoglossal canal: systematic review on imaging anatomy, clinical findings, and endovascular management. J Neurosurg 2015;122:883903 CrossRef Medline

15. van Dijk JM, terBrugge KG, Willinsky RA, et al. Clinical course of cranial dural arteriovenous fistulas with long-term persistent cortical venous reflux. Stroke 2002;33:1233-36 CrossRef Medline

16. Davies MA, TerBrugge K, Willinsky R, et al. The validity of classification for the clinical presentation of intracranial dural arteriovenous fistulas. J Neurosurg 1996;85:830-37 CrossRef Medline

17. Caton MT, Callen AL, Copelan AZ, et al. Jugular venous reflux can mimic posterior fossa dural arteriovenous fistulae on MRI/MRA. Am J Roentgenol 2020 Sep 2. [Epub ahead of print] CrossRef Medline

18. Borden JA, Wu JK, Shucart WA. A proposed classification for spinal and cranial dural arteriovenous fistulous malformations and implications for treatment. J Neurosurg 1995;82:166-79 CrossRef Medline
19. Halbach V, Hieshima G, Higashida R, et al. Carotid cavernous fistulae: indications for urgent treatment. AJR Am J Roentgenol 1987;149:58793 CrossRef Medline

20. Djindjian R, Merland JJ. Normal super-selective arteriography of the external carotid artery. In: Djindjian R, Merland JJ. SuperSelective Arteriography of the External Carotid Artery. SpringerVerlag: Berlin Heidelberg; 1978:1-123

21. Awad IA, Little JR, Akarawi WP, et al. Intracranial dural arteriovenous malformations: factors predisposing to an aggressive neurological course. J Neurosurg 1990;72:839-50 CrossRef Medline

22. Kim MS, Han DH, Kwon OK, et al. Clinical characteristics of dural arteriovenous fistula. J Clin Neurosci 2002;9:147-55 CrossRef Medline

23. Matsushima K, Kawashima M, Matsushima T, et al. Posterior condylar canals and posterior condylar emissary veins: a microsurgical and CT anatomical study. Neurosurg Rev 2014;37:115-26 CrossRef Medline 